\title{
ON THE CLASSES OF D-NORMAL OPERATORS AND
} D-QUASI-NORMAL OPERATORS ON HILBERT SPACE

\author{
M. DANA AND R. YOUSEFI
}

Abstract. The purpose of this paper is to introduce some new classes of operators, called $[D N]$, $[n D N],[D Q N],[n D Q N]$, associated with a Drazin invertible operator using its Drazin inverse. $[n D N]$ and $[n D Q N]$ operatots extend the notion of $[D N]$ and $[D Q N]$ operators, respectively. The relations between these classes and some basic properties of these operators are studied in this study.

Mathematics subject classification (2010): 47B15, 47B20, 47A15, 15A09.

Keywords and phrases: Drazin inverse, n-normal operators, quasi-normal operators, n-power quasinormal operators.

\section{REFERENCES}

[1] O. M. Ahmed, On The Class of n-Power Quasi-Normal Operators on Hilbert Space, Bulletin of Mathematical Analysis and Applications 3 (2011), no. 2, 213-228, .

[2] S. A. Al-Zuraiqi And A. B. Patel, On n-normal Operators, General Mathematics Notes 2 (2010), no. $1,61-73$.

[3] A. Ben-Israel, T. N. E. Greville, Generalized Inverses: Theory and Applications, second ed., Springer Verlag, New York, 2003.

[4] A. BRown, On a class of operators, Proc. Amer. Math. Soc 4 (1953), 723-728.

[5] S. L. CAmpbell, C. D. Meyer, Generalized Inverse of Linear Transformations, Pitman, London, 1979 (Dover, New York, 1991).

[6] S. R. CARAdus, Operator Theory of the Generalized Inverse, Science Press, New York, 2004.

[7] J. B. Conway, A Course in Functional Analysis, Second Edition, Springer Verlag, Berlin Heildelberg - New York 1990.

[8] M. R. EMbry, Conditions implying normality in Hilbert space, Pacific. J. Math. 18 (1966), 457-460.

[9] R. Grone, C. R. Johnson, E. M. SA, H. Wolkowicz, Normal matrices, Linear Algebra Appl. 87 (1987), 213-225.

[10] P. R. Halmos, A Hilbert Space Book, Springer-Verlag, New York, 1982. 